\title{
Cartografar variedades de língua: código de linguagem e posicionamento
}

\section{Cartography and linguistic varieties: linguistic code and positioning}

Bruno Deusdará*

Universidade do Estado do Rio de Janeiro, Rio de Janeiro / Brasil brunodeusdara@gmail.com

Décio Rocha

Universidade do Estado do Rio de Janeiro, Rio de Janeiro / Brasil rochadm@uol.com.br

Poliana Coeli Costa Arantes

Universidade do Estado do Rio de Janeiro, Rio de Janeiro / Brasil polianacoeli@yahoo.com.br

Resumo: Este artigo interroga verdades instituídas a respeito da noção de variedade linguística, propondo uma discussão que parte da perspectiva discursiva, em especial da noção de código de linguagem, que, segundo Maingueneau (2001), afasta-se de uma imagem monolítica de língua, apresentando-se como mais um dispositivo de construção de posicionamento(s) no campo discursivo, lidando com uma mescla de línguas em sua pluralidade de registros como modo de apropriação da linguagem. Como método, o estudo está pautado pela cartografia, reconhecendo sua produtividade na análise de um texto que reúne características do discurso literário e explicita sua afinidade com o tema da variação linguística. Os resultados alcançados evidenciam

\footnotetext{
* O autor agradece à Faperj pela concessão de bolsa do Programa Jovem Cientista do Nosso Estado (Processo no 21.4710. Edital 06/2015)
} 
a impossibilidade de dissociação entre os usos linguísticos e o(s) posicionamento(s) que esses usos ajudam a instituir.

Palavras-chave: código de linguagem; posicionamento; cartografia; Patativa do Assaré.

Abstract: In this paper, we question instituted truths regarding the concept of linguistic variety, proposing a discussion based on a discursive perspective, especially an approach of the concept of linguistic code, which, according to Maingueneau, departs from the idea of a monolithic image of languages, presenting itself as a further device for constructing a positioning in the discursive field - a device which deals with a mixture of languages in their plurality of registers as the path to language appropriation. Our methodological approach is built on cartography, a procedure which highlights its productivity in confronting a text which gathers characteristics of literary discourse and makes explicit its affinity with the topic of linguistic variation. Results corroborate the impossibility of dissociation between linguistic uses and the positioning(s) that these uses contribute to establish.

Keywords: linguistic code; positioning; cartography; Patativa do Assaré.

Recebido em: 7 de setembro de 2016.

Aprovado em: 16 de novembro de 2016.

\section{Considerações iniciais}

Partindo da premissa de que todo conhecimento se produz como resposta a indagações situadas sócio-historicamente, elaboramos, no presente texto, um percurso de questionamentos em diálogo com nossa prática profissional na formação de professores na área de Letras. Entre os diversos tópicos da grade curricular do curso de Letras, aquele que ainda parece encontrar maior resistência, não obstante a consolidação e ampla divulgação científica dos resultados das pesquisas em sociolinguística, é o das variedades de língua. Por essa razão, decidimos investir no referido tema por entradas diversas daquelas experimentadas mais comumente.

Iniciaremos por uma delimitação do território conceitual a partir do qual propomos a abordagem da referida temática, destacando 
especialmente a produtividade da noção de código de linguagem, que remonta aos trabalhos de Bakhtin (2013) acerca da polifonia e que explora o vínculo indissociável entre a variedade dos usos linguísticos e o posicionamento para cuja constituição esses usos contribuem. $\mathrm{Na}$ sequência, apresentamos o debate relativo à cartografia como princípio filosófico e como método de pesquisa. Investimos na análise de texto literário, explicitando a diversidade de enunciadores que se inscrevem na enunciação, bem como sua articulação na construção de um posicionamento, em diálogo que transversaliza a perspectiva discursiva e o método da cartografia. Por fim, ressaltamos linhas de intervenção possíveis no campo da formação de professores de língua.

\section{Orientação discursiva e a noção de código de linguagem}

Neste item, delineamos as ferramentas conceituais com as quais investiremos no debate acerca da variedade linguística, considerando a perspectiva discursiva que temos praticado. Para uma breve caracterização do entendimento que temos da relação entre discurso e sua exterioridade, ressaltamos dois princípios: i) o vínculo entre as ações verbais e não verbais é simultâneo e não linear; ii) o verbal não apenas representa as ações não verbais, mas contribui para sua instituição. Dito de outro modo,

o discurso tem, sim, algum poder de representação de algo que já não é o mundo, pois, ao se referir a esse mundo, ele congela o tempo, altera distâncias, oferecendo-nos um retrato de dado momento, o retrato de uma realidade passada e/ou de uma nova paisagem que não coincide com as coordenadas geográficas verificadas no 'mundo ao vivo' (ROCHA; DEUSDARÁ, 2011, p. 173).

Consideramos que os textos não são produzidos no interior de uma língua (fechada, compacta), mas por intermédio de um código de linguagem, constituído em uma interlíngua, isto é, em um espaço de negociação entre diversas variedades de língua. Acreditar que a língua seja mero instrumento plenamente formado a veicular uma dada informação implicaria assumir uma concepção comunicacional das trocas linguageiras, cuja falácia já foi denunciada por muitas versões discursivas no tratamento das práticas de linguagem. 
Para Maingueneau (2006), não se poderia conceber uma língua em um estado anterior aos seus usos efetivos, inscritos num espaço institucional delimitado: "Para surgir uma língua como totalidade, para que se tracem as fronteiras de um espaço estabilizado, vinculado com uma comunidade, é necessária a referência a um corpus, um ambiente de uso restrito e prestigioso, particularmente uma literatura" (MAINGUENEAU, 2006, p. 197). Desse modo, não se poderia, segundo o autor, remetendo-se especificamente à escrita literária, supor uma língua como um universo delimitável previamente aos textos nos quais ela se realiza e em função do posicionamento no qual investe toda a sua construção de sentidos: "as obras não se desenvolvem sobre a língua, mas intervêm na interação de seus múltiplos planos" (MAINGUENEAU, 2001, p. 101, grifo do autor).

Outro modo de argumentar favoravelmente à impossibilidade de se assumir a língua como instância anterior a todas as situações de troca verbal residiria na definição do conceito de interlíngua, que implica "as relações, numa determinada conjuntura, entre as variedades da mesma língua, mas também entre essa língua e as outras, passadas ou contemporâneas" (MAINGUENEAU, 2001, p. 104).

Nesse sentido estabelecido por Maingueneau (2001), a língua não precede às obras ou ao uso que delas se faz, mas intervém na interação e se constitui como parte integrante desse processo. Retomando a lógica da reflexividade da instância enunciativa, Maingueneau (2006) a estende a seu modo de conceituar a língua a partir de sua indissociabilidade das instituições que a tornam possível, em especial a literatura: "a língua como um sistema se constitui e se mantém através do espelho que torna possível um conjunto privilegiado de enunciados subtraídos ao intercâmbio cotidiano" (MAINGUENEAU, 2006, p. 198).

Estabelece-se, com isso, uma identidade entre língua e a existência de uma literatura, que, em sentido amplo, é definida como "um corpus de enunciados estabilizados, valorizados esteticamente e reconhecidos como fundadores de uma dada sociedade" (MAINGUENEAU, 2006, p. 198). Assume-se a língua como contraface de um sistema de produção, circulação e avaliação de enunciados.

Não é possível, segundo o autor, referir-se genericamente a uma língua que não esteja marcada pelo posicionamento que seus usos contribuiriam para constituir. Para dar conta dessa hipótese, o autor elabora a noção de código de linguagem. Ressaltando uma dupla acepção de "código", que remete tanto a um sistema de regras de signos, quanto 
às prescrições que lhe dão sustentação, a noção remete ao "uso da língua que a obra implica [que] se mostra como a maneira em que é necessário enunciar" (MAINGUENEAU, 2001, p. 104, grifo do autor).

Com isso, interrogamos a unidade imaginária da língua, concebida como realidade assumida como um ente independente das instituições que delimitam usos, conferem unidade, constituem e divulgam sua pretensa homogeneidade. Para Maingueneau (2001, p. 103), as obras literárias cumprem função determinante, pois "aumentam através de sua escrita o valor de uma língua que, valorizada desse modo, deve aumentar o valor de sua escrita". A indissociabilidade entre língua e instituições o leva à seguinte hipótese: a língua não constitui uma base, ela é parte integrante do posicionamento da obra literária. Em outras palavras, recuperando a perspectiva polifônica de M. Bakhtin (2013), ainda que sem a explicitar, um texto não possuirá significados próprios que não estejam integrados e em consonância com o posicionamento no qual se sustenta.

Tal negociação-confrontação entre variedades linguísticas se produz em diferentes níveis: no interior de uma mesma língua, quando se fala de "variedades internas" (a exemplo dos usos sociais diversificados, níveis de língua em função da situação de interlocução) e também no afrontamento de línguas diversas, "variedades externas" de idiomas. Maingueneau e Cossutta (1995) não deixam de assinalar a relatividade de sintagmas como "variedades internas" e "variedades externas" de língua, uma vez que a distância entre a língua estrangeira e a "não estrangeira" não é dada em si, dependendo, antes, de cada posicionamento que se assume no campo dos discursos: para um filósofo do século XVII, o latim não pode ser tido como "língua estrangeira" (MAINGUENEAU; COSSUTTA, 1995, p. 121).

Um mesmo tipo de reflexão é desenvolvido pelos teóricos supracitados no âmbito dos textos literários. Recusando-se a subscrever um determinado modo (preconceituoso) de articulação entre língua e literatura, segundo o qual a formação da língua precederia a produção de obras, os autores sustentam que "a produção literária não é condicionada por uma língua completa e autárquica que lhe seria exterior, mas entra no jogo de tensões que a constitui" (MAINGUENEAU; COSSUTTA, 1995, p. 101). Em outras palavras, "a maneira como a obra gere a língua faz parte do sentido dessa obra" (MAINGUENEAU; COSSUTTA, 1995, p. 104). Desse modo, os autores praticamente subvertem a ideia de língua pelo recurso à noção de interlíngua, entendida como uma 
interação de línguas e de usos linguísticos, resultante das "relações, numa determinada conjuntura, entre as variedades da mesma língua, mas também entre essa língua e as outras, passadas ou contemporâneas" (MAINGUENEAU; COSSUTTA, 1995, p. 104). É precisamente essa negociação com variedades de uma mesma língua e com outras línguas o que autoriza Maingueneau (2001) a falar de "plurilinguismo interno" e "plurilinguismo externo", respectivamente.

\section{A construção do problema}

Se as forças de conservação parecem indicar o receio da diversidade, o medo da pretensa desqualificação dos usos, a insistência no mito da ascensão social pelo domínio de uma variante, o reconhecimento da variação linguística não raro produziu posicionamentos tais como "o que vale é a comunicação", "se é compreendido, não importa a regra que utiliza". Já no âmbito da formação de professores de língua estrangeira, citaríamos, a título de exemplo, a preferência pelo francês da França, da Bélgica, da Suíça ou do Canadá que nos fora explicitada em sala. Naquele momento, mais do que uma recusa da língua falada em países como Congo, Haiti, ou mesmo Argélia e Tunísia, a preferência apresentada parecia sustentar fortemente a ideia de língua que se define por um primado da unidade sobre a diversidade. Exemplos outros, como o estranhamento diante de vídeos de falantes austríacos ou suíços, em língua alemã, indicam não apenas uma concepção prévia acerca das línguas, mas igualmente um efeito dos materiais didáticos de alemão como língua estrangeira. Esses materiais dão clara preferência ao Hochdeutsch, circunscrevendo a diversidade de usos de língua a lições específicas.

Esse mesmo cenário que se atualiza na aula de língua estrangeira também se verifica na de língua portuguesa, com uma pequena diferença, talvez: com um certo "refinamento analítico", chega-se à criação de uma tipologia de "desvios". Nessa tipologia, o "desvio" ora é tratado como o erro do ignorante que não sabe a que se opõe, ora como a "variação estilística" de quem no fundo conhece a língua. Desse modo, o senso comum costuma traçar uma fronteira quase inegociável entre, por um lado, a incorreção de "a gente vamu", "nós também vai" e, por outro, a "forma de falar" dos escolarizados que procedem à redução de formas verbais em situações diversas, como ocorre em "falá", "sô", "tá bom" ou "vamu". 
Acrescentemos ainda outros casos em que a prescrição vem encontrando resistência. Mesmo na escrita, inclusive em textos acadêmicos, o emprego do sujeito em posposição parece determinar que o verbo permaneça no singular, independentemente do número do sintagma nominal a que se refere o verbo ("Chegou por volta do meiodia todos os alunos"), ou ainda as construções da passiva sintética, que sempre acabam ganhando uma feição de indeterminação do sujeito, em enunciados como "observa-se muitos casos de...".

Como elemento que contribui para a colocação do problema que apresentaremos, nossas observações ressaltam a ideia de que a diversidade, no âmbito de nossa prática cotidiana, parece emergir mais como um tema do que um eixo estruturante das grades curriculares. Outros exemplos reforçam essa intuição. Extraímos dois excertos de páginas eletrônicas cujo projeto é oferecer explicação didática do tema da variação linguística, na Educação Básica. Trata-se de materiais que circulam em páginas eletrônicas a que se pode facilmente chegar, a partir de busca com o descritor "variação linguística".

No primeiro deles, os elementos em negrito "o padrão formal" e "o nível informal” já antecipam uma leitura indesejável do referido tema:

O padrão formal está diretamente ligado à linguagem escrita, restringindo-se às normas gramaticais de um modo geral. Razão pela qual nunca escrevemos da mesma maneira que falamos. Este fator foi determinante para a (sic) que a mesma pudesse exercer total soberania sobre as demais.

Quanto ao nível informal, este por sua vez representa a linguagem do dia a dia, das conversas informais que temos com amigos, familiares etc.

Compondo o quadro do padrão informal da linguagem, estão as chamadas variedades linguísticas, as quais representam as variações de acordo com as condições sociais, culturais, regionais e históricas em que é utilizada (sic) (DUARTE, [s.d.], grifos da autora).

Note-se, nesse primeiro exemplo, que a oposição construída se articula do seguinte modo: padrão formal + língua escrita + normas gramaticais x nível/padrão informal + linguagem do dia a dia + conversas com amigos e familiares + condições sociais, culturais, regionais e históricas. Ou ainda: escrevemos x falamos. Situação que nos parece 
preocupante sob diferentes aspectos: não se reconhece que também pode haver um padrão na língua que se fala; não se apontam os desvios que vêm invadindo a língua portuguesa escrita (há muito já não se faz mesóclise; a passiva sintética...).

No exemplo a seguir, a apresentação do tema se dá de modo menos esquemático:

Toda língua possui variações linguísticas. Elas podem ser entendidas por meio de sua história no tempo (variação histórica) e no espaço (variação regional). As variações linguísticas podem ser compreendidas a partir de três diferentes fenômenos.

1) Em sociedades complexas convivem variedades linguísticas diferentes, usadas por diferentes grupos sociais, com diferentes acessos à educação formal; note que as diferenças tendem a ser maiores na língua falada que na língua escrita;

2) Pessoas de mesmo grupo social expressam-se com falas diferentes de acordo com as diferentes situações de uso, sejam situações formais, informais ou de outro tipo;

3) Há falares específicos para grupos específicos, como profissionais de uma mesma área (médicos, policiais, profissionais de informática, metalúrgicos, alfaiates, por exemplo), jovens, grupos marginalizados e outros. São as gírias e jargões.

Assim, além do português padrão, há outras variedades de usos da língua cujos traços mais comuns podem ser evidenciados abaixo [...] (NERY, 2007).

Não se pode deixar de ouvir nesses enunciados a ressonância de outros, que nos soam como concessivos: "é verdade que talvez não se deveria falar assim, mas...". Essa concessão confirma o poder da prescrição, assegura o lugar dos juízes da língua. O que se perde nessa insistência no mesmo não é apenas o reconhecimento da variedade.

No que tange à problemática em direção à qual pretendemos constituir nossas indagações, diríamos o seguinte: expressando-se em graus variados de cristalização, a imagem de língua configurada a partir de um polo normatizador parece se reiterar indefinidamente, inclusive em momentos em que o que se tematiza é justamente a investigação do tópico relativo à variação linguística. Mais do que isso, o deslocamento 
entre os polos da unidade e da variedade sustenta-se em uma imagem do pensamento hegemônica, a do pensamento arborescente: "A árvore ou raiz inspiram uma triste imagem do pensamento que não pára de imitar o múltiplo a partir de uma unidade superior, de centro ou de segmento" (DELEUZE; GUATTARI, 2007, p. 26).

Aproveitamos a menção ao pensamento de Deleuze e Guattari (2007) para também já indicar uma entrada metodológica bastante produtiva: a cartografia. Empregamos aqui "cartografia" ampliando o uso que se faz em geografia, inspirados na proposta de Rolnik (2007, p. 23), para quem

paisagens psicossociais também são cartografáveis. A cartografia, nesse caso, acompanha e se faz ao mesmo tempo que o desmanchamento de certos mundos - sua perda de sentido - e a formação de outros: mundos que se criam para expressar afetos contemporâneos, em relação aos quais os universos vigentes tornaram-se obsoletos.

Diante da diversidade de materiais que indicam optar pela cartografia como método, pautamo-nos aqui pelas reflexões que vêm sendo sistematizadas por Passos, Kastrup e Escóssia (2009) e Passos, Kastrup e Tedesco (2014).

Operando com a própria etimologia da palavra "método" como um dispositivo "analisador" das expectativas que tradicionalmente se inscrevem na adoção de um método de pesquisa, Passos e Barros (2009, p. 17) consideram que o desafio da cartografia reside na seguinte reversão: "não mais um caminhar para alcançar metas pré-fixadas (metáhódos), mas o primado do caminhar que traça, no percurso, suas metas. A reversão, então, afirma um hódos-méta".

Um desafio para o qual um investimento pelo método da cartografia nos parece bastante positivo: afirmar a positividade da variedade. Para isso, é necessário afastar-se dos juízos que não cessam de reenviar a diversidade linguística ao poder de atração do mesmo.

\footnotetext{
${ }^{1} \mathrm{O}$ conceito de analisador foi forjado por Guattari para designar aquele ou aquilo que provoca análise, quebra, separação, explicitação dos elementos de dada realidade institucional. A esse respeito, ver Rossi e Passos (2014).
} 


\section{Cartografia e a coemergência sujeito-mundo-língua}

Nosso interesse pela cartografia se sustenta nas seguintes premissas: i) cartografamos para interrogar uma ideia instituída de língua como unidade/centro; ii) assumimos como campo de intervenção o território da formação de pesquisadores e profissionais de língua.

Ao questionar os dualismos instalados na "imagem do pensamento ocidental" - nesse momento, Deleuze e Guattari (2007) se referem às disciplinas que vão da psicanálise à linguística -, os autores interrogam a fragilidade da suposição de uma instância diretriz do pensamento, uma pretensa unidade a partir da qual tudo se pusesse a funcionar. $\mathrm{O}$ argumento para sustentação desse questionamento já é uma espécie de cartografia: "Os fios da marionete, considerados como rizoma ou multiplicidade, não remetem à vontade suposta de um artista ou de um operador, mas à multiplicidade das fibras nervosas que formam por sua vez uma outra marionete seguindo outras dimensões conectadas às primeiras" (DELEUZE; GUATTARI, 2007, p. 16).

O mérito de uma argumentação dessa natureza residiria, a nosso ver, em incluir o "artista" nas operações que realiza com a "marionete". Em outros termos, recusa-se o pretenso apagamento do pesquisador nas atividades de investigação que propõe, abrindo a possibilidade de integrá-las numa vasta rede que atravessa as comunidades de pesquisa, a circunscrição social da instituição, o aparato jurídico que regula as formas de vida, as condições de financiamento e de organização das relações econômicas, a ativação de valores ético-políticos dos indivíduos e grupos em interação.

Como método de pesquisa, a cartografia assume como princípio a ideia de que toda pesquisa é intervenção: "a intervenção sempre se realiza por um mergulho na experiência que agencia sujeito e objeto, teoria e prática, num mesmo plano de produção ou de coemergência" (PASSOS; BARROS, 2009, p. 17). Articulando essa discussão com nossa proposta de trabalho, ressaltamos nosso desejo de intervir no campo da formação de professores de língua. Desse modo, o investimento no método da cartografia nos convoca a estarmos atentos aos encontros que se realizam em diferentes circunstâncias, "às virtualidades que estalam nos agenciamentos e que são oriundos das desestabilizações que, no processo de trabalho, acometem tanto o pesquisador quanto seu objeto de estudo, seu campo" (ROMAGNOLI, 2009, p. 171). 
Desse modo, desejamos ainda destacar dois aspectos que nos parecem fundamentais para aproximar a discussão a respeito do método da cartografia de análise que ora propomos. Partindo da recusa da neutralidade do pesquisador, avançamos na diretriz da pesquisa cartográfica, que se realiza "por pistas que orientam o percurso da pesquisa sempre considerando os efeitos do processo de pesquisar sobre o objeto da pesquisa, o pesquisador e seus resultados" (PASSOS; BARROS, 2009, p. 17). Nesse sentido, os dois aspectos que desejamos destacar remetem à pesquisa como um mergulho na experiência $\mathrm{e}$, em decorrência disso, se torna inescapável a análise das implicações do pesquisador com o campo.

I) Mergulho na experiência: o processo de pesquisa concebido como um mergulho na experiência nos permite ressaltar a investigação sem reduzi-la a um poder de explicação do real. Todo conhecimento se efetua a partir de um processo de interações diversas, sendo que muitas delas se silenciam em sua narrativa. Entendemos que uma intervenção efetiva a esse respeito, na formação de professores, vem demandando novas entradas, tais como aquela que vem da articulação entre os usos linguísticos, os suportes e os posicionamentos que contribuem para configurar.

II) Implicações: todo conhecimento se produz em um campo de implicações que requer análise das forças em jogo. Desse modo, longe de pretender observar o mundo a partir de um ponto de vista desencarnado, a cartografia assume justamente que todo projeto de investigação ganha consistência ao recortar o campo social, propor certo manejo de suas linhas de configuração. Se considerarmos como território existencial ao qual nossa reflexão se dirige uma figura de professor de língua que se atualiza em uma encomenda constante de saberes enciclopédicos sobre a referida língua, sua normatividade, a cartografia que nos dispomos a realizar interroga as verdades estabelecidas, os sentidos cristalizados.

\section{Um exercício de análise}

Retomando a reflexão de Maingueneau $(2001,2006)$ sobre o texto literário - reflexão que ora pretendemos estender a toda e qualquer manifestação verbal -, é muito comum a dissociação entre a construção de uma língua e a produção da literatura nessa língua. Em outras palavras, o autor assegura ser bastante recorrente a ideia de que primeiro se constituiria uma língua e somente mais tarde se instituiria sua literatura. 
Tendo em vista nosso projeto de estender o que diz o autor acerca do texto literário a toda e qualquer manifestação verbal, sustentaremos que a produção de textos é concomitante à formação de uma língua. Propomos uma inversão nas seguintes formas de tratar os fatos de linguagem: (i) a partir de uma posição em que o sujeito não se desloca da rejeição a qualquer coisa que se distancie da norma padrão; (ii) a partir de uma posição em que o sujeito aceita algum grau de distanciamento, mas como uma concessão feita, muitas vezes em nome de uma atitude politicamente correta.

Como se percebe, nenhuma das posições acima elencadas é produtiva ou reflete com adequação os processos de construção de uma língua. Aliás, falar de "uma língua" já é, como bem queria Nietzsche (1978), uma concessão que se faz à produção do conceito que mata a realidade sempre em movimento do fenômeno: não há uma língua, mas línguas que, por igualação do não igual, metaforicamente, resultam na construção (abstrata) do conceito. Na verdade, falar de "uma língua" pressupõe a naturalização de um dado perfil do verbal, relegando aos demais perfis (existentes e em formação) o lugar de "formações desviantes". Como lidamos aqui com o tema do preconceito (linguístico), consideramos produtivo aproximar da reflexão que acabamos de fazer, outra reflexão também da ordem do preconceito (desta vez, sexual), no sentido de mostrar que "aceitar" o vasto leque de variações linguísticas (como se tais variações precisassem de qualquer aceitação!) está longe de constituir uma atitude saudável e comprometida com valores éticos importantes para a formação do professor de línguas. Citamos, então, o texto de referência a essa outra modalidade de preconceito:

Mesmo que não consideremos que a homossexualidade seja anormal ou patológica, cada vez que tentamos achar um momento ou ocasião que a origina, nós naturalizamos a heterossexualidade e ocultamos um dos mecanismos de produção da anormalidade, isto é, a naturalização da sexualidade. Para não incorrer nesse erro conceitual e político, teríamos que substituir a questão de uma causa da sexualidade para problematizar que mecanismos tornam alguns sujeitos aceitáveis, normalizados, coerentes, inteligíveis e outros desajustados, abjetos. Sairíamos de uma busca pela causa para uma problematização dos mecanismos de produção das abjeções(COLLING, 2015, p. 24). 
Transportando a reflexão de Colling (2015) para a nossa questão, diremos que, ainda que não consideremos a variação linguística anormal, ao buscarmos o "momento ou ocasião" de sua origem, naturalizamos a língua padrão "e ocultamos um dos mecanismos de produção da anormalidade”, neste caso, a própria naturalização dessa língua padrão. Importante perceber aqui que a "anormalidade" não é uma marca intrínseca ou essencial da variação. E não poderia ser diferente, uma vez que entendemos que o preconceito linguístico é algo que vem sempre acompanhado de outras formas de preconceito: se há quem abomine formas como "a gente vamos" ou "Framengo", isso nada tem a ver com a qualidade das construções, e sim com a parcela da população que efetivamente as produz (e com a qual o cidadão "cultivado" não deseja se identificar). É uma forma de preconceito que inclui, portanto, restrições no plano socioeconômico, se lembrarmos que, em textos como "Povoaram os degraus muita gente de sorte", de Camilo Castelo Branco, ou "a gente... removem o temor frio", de Camões, tais construções se explicam como casos de silepse, e como rotacismo formas igualmente atestadas em Camões ("frecha" por "flecha").

Procurando explicitar entradas na materialidade linguística para o debate conceitual a que procedemos neste artigo, nossa análise privilegiará a abordagem de um poema de Antônio Gonçalves da Silva, o Patativa do Assaré. Trata-se de texto marcado por uma dupla característica: sua inscrição no discurso literário e sua afinidade com o tema da variação linguística.

O poema "Ao leitô", de Patativa do Assaré (2006, p. 13), é organizado em um corpo de cinco quartetos, totalizando vinte versos. Por sua extensão reduzida, reproduzimos a seguir todo o poema:

Ao Leitô

Leitô, caro amigo, te juro, não nego,

Meu livro te entrego bastante acanhado,

Por isso te aviso, me escute o que digo,

Leitô, caro amigo, não leia enganado.

É simpre, bem simpre, modesto e grossêro,

Não leva o tempero das arte e da escola,

É rude o poeta, não sabe o que é lira,

Saluça e suspira no som da viola. 
Tu nele não acha, tarvez, com agrado

Um trecho engraçado que faça uma escôia,

Mas ele te mostra com gosto e vontade,

A luz da verdade gravada nas fôia.

Não vá percurá neste livro singelo

Os canto mais belo das lira vaidosa,

Nem brio de estrela, nem moça encantada,

Nem ninho de fada, nem chêro de rosa.

Em vez de prefume e do luxo da praça,

Tem chêro sem graça de amargo suó,

Suó de caboco que vem do roçado,

Com fome, cansado e queimado de só.

O texto se apresenta em registro escrito, mantendo, contudo, a natureza oral que marca sua invenção, como bem o revela o esquema de rimas dos quartetos (ABCB). Tal disposição do poema em quartetos, conforme registrado, é, certamente, uma escolha do escrevente e, ao que tudo indica, poderia ser outra. Basta, por exemplo, que se considere que, sob o esquema $\mathrm{ABCB}$, um outro esquema rímico pode ser explicitado numa estrutura de estrofes de oito (e não quatro) versos. A título de exemplo, reconfiguremos o segundo quarteto sob a forma de oitava:

$$
\begin{aligned}
& \text { É simpre, bem simpre } \\
& \text { modesto e grossêro, } \\
& \text { Não leva o tempero } \\
& \text { das arte e da escola, } \\
& \text { É rude poeta, } \\
& \text { não sabe o que é lira, } \\
& \text { Saluça e suspira } \\
& \text { no som da viola }
\end{aligned}
$$

(PATATIVA DO ASSARÉ, 2006, p. 13, adaptado).

Sob a forma de oitavas, explicita-se a métrica de versos pentassílabos que seguem um esquema rímico do tipo ABBCDEEC. ${ }^{2}$ Identidades que se recompõem, formas diversas (a do quarteto e a da oitava) sustentadas pela presença de forças que passam pela oralidade do texto, em nada mitigada por sua inscrição no suporte escrito.

\footnotetext{
${ }^{2}$ Tal esquema rímico só não se verifica na primeira oitava.
} 
Como se percebe, a inscrição na modalidade escrita da língua denuncia uma certa vontade de reproduzir o mais fielmente possível o modo como se enuncia oralmente. Com efeito, marcas como "leitô" (leitor), "suó" (suor), "chêro" (cheiro), "só" (sol), "simpre" (simples), "prefume" (perfume), dentre outras, buscam recuperar um certo modo de enunciar oralmente. Tal escolha remete minimamente a uma dupla realidade: (i) a língua como suporte de marcas que distinguem a inscrição em uma região e em uma classe socioeconômica, como parece ser o caso de "só", "simpre" e "prefume"; (ii) a língua como suporte de marcas indicativas de uma fala informal, que atravessa diferentes regiões e diferentes classes socioeconômicas, a exemplo de "leitô", "suó", "chêro".

Em seu registro escrito, o texto de Patativa denuncia o encontro de, no mínimo, dois enunciadores: de um lado, o poeta-recitador, cujas escolhas lexicais, morfológicas, sintáticas se mostram na oralidade do texto; de outro, o poeta-escrevente, que, de posse de um saber escritural e baseado na realização fonética do texto recitado, busca uma grafia que lhe corresponda tanto quanto possível. O hiato verificado entre o momento da criação do poema e a sua transcrição no papel é atestado pelo próprio Patativa (CARVALHO apud PINHEIRO, 2006, p. 141142): "Faço a primeira estrofe e deixo retida na memória. A segunda, do mesmo jeito. A terceira e assim por diante. Pode ser um poema de trinta estrofes. Quando eu termino, estou com todas elas retidas na memória. Aí é só passar para o papel. Sempre fiz verso assim".

Que relação mantêm essas observações com a ideia de código de linguagem?

Num plano macro, uma leitura muito recorrente é a da variação linguística em relação a um padrão. O plano macro de análise é aquele que, ao privilegiar as formas constituídas, entretém relação de muita proximidade com os poderes instituídos. Por essa razão, naturaliza toda e qualquer variação que tenha o sabor de "sudeste maravilha" "chêro", "leitô", "suó" - e, em contrapartida, penaliza as formas que trazem a marca de uma comunidade discursiva desprestigiada: no plano lexical, "saluça" (forma que, ironicamente, é dicionarizada), "percurá", "prefume"; no plano sintático, "[...] o tempero das arte e da escola", "Os canto mais belo das lira vaidosa".

O que nos parece importante, contudo, é perceber a inadequação de uma perspectiva sobre a língua que faça um padrão se sobrepor a - e mesmo anteceder no tempo - formas tidas como variantes (sempre de 
menor valor). No texto de Patativa do Assaré, assistimos inclusive a um verdadeiro trabalho da língua em construção, quando, por exemplo, deparamo-nos com formas que atestam a força da metátese, como "percurá", "prefume", cumprindo exatamente um mesmo trabalho na língua já concluído em formas como "semper" $\rightarrow$ "sempre", "inter" $\rightarrow$ "entre" (mantendo-se ainda a forma prefixal "inter-"), "praecunctare" $\rightarrow$ "perguntar" (mantendo-se hoje também a forma não padrão "preguntar", mais próxima de sua origem latina). ${ }^{3}$ Tem-se aí um flagrante de língua em construção, reafirmando, desse modo, a pertinência do conceito de código de linguagem.

\section{Considerações finais}

Nestas considerações finais, propomos uma articulação entre as análises realizadas e o que fora objeto de nossa discussão metodológica a respeito da cartografia. Três das pistas deixadas pela reflexão cartográfica de Passos, Kastrup e Escóssia (2009) nos interessam de perto: a indissociabilidade entre conhecer e transformar (pista 1); a suspensão da representação de objetos em proveito da cartografia de processos (pista 3); o confronto entre formas em equilíbrio e forças desestabilizadoras (pista 5).

Comecemos pela pista referente ao primado dos processos em detrimento da representação de identidades (con)formadas. A experiência de leitura do poema de Patativa do Assaré, com tudo aquilo que de oralidade ele guarda para além de um certo imobilismo propiciado pela escrita, é uma experiência que nos faz viver a realidade de uma língua que ainda não "é", mas que "está sendo". Com efeito, muitas vezes nos referimos ao português brasileiro como objeto totalizado, representado em uma modalidade padrão que se faz acompanhar de diversas outras modalidades ditas variantes. O poema para o qual nos voltamos interessa à reflexão sobre código de linguagem justamente por explicitar a condição de uma língua ainda em construção - aliás, trabalhada por todos os que nela enunciam, como ocorre com qualquer uma. Senão, vejamos: (i) atualizando a ideia de metátese, que, na formação do português, caracteriza a passagem de "pro-" $\rightarrow$ "por-", "inter-" $\rightarrow$ "entre-", reencontramos no

\footnotetext{
${ }^{3}$ Sobre a presença da metátese no português brasileiro, ver Hora, Telles e Monaretto (2007).
} 
texto de Patativa formas como "percurá" e "prefume", que, por óbvio, vêm cumprindo seu itinerário de alterações ao longo do tempo; (ii) dando continuidade aos fenômenos de rotacismo já consagradas em "eclesia" $\rightarrow$ "igreja", "blanco" $\rightarrow$ "branco", o texto de Patativa exibe a forma "simpre", reafirmando uma tendência que distingue o português dentre as línguas neolatinas ("simples" $\rightarrow$ "simpre").

Todo o exposto põe em cena a pista 5 - formas cristalizadas não são imunes ao que há de renovador nas forças desestruturantes. Uma língua é feita de formas que, até certo ponto, parecem estáveis - temos a experiência de poder nos comunicar sem perceber grandes alterações - que, contudo, estão em movimento continuamente. Apostamos na estabilidade das formas, que é o que nos garante falar uma língua, mas também damos prova de uma clara intuição a respeito dos deslocamentos que a língua pode/deve sofrer. O texto de Patativa ainda oferece evidências do mesmo tipo de movimento da língua no plano sintático, a saber, a formação do plural do sintagma nominal com marcação apenas no primeiro elemento: "o tempero das arte e da escola" e "gravada nas fôia".

Por último, diremos que todo conhecimento expressa uma intervenção sobre a realidade e não apenas uma explicação gerada à distância. Ressaltando os movimentos de análise propostos, percebemos, a título de exemplo, uma fragilização das fronteiras entre as áreas de estudos de literatura e de língua. Aqui, o texto literário é apropriado não apenas como pretexto para análise de fenômenos linguísticos, sendo igualmente consideradas diversas dimensões que concorrem para sua elaboração. Do mesmo modo, procede-se a uma análise para a qual são convocados saberes diversos do campo dos estudos linguísticos, em semelhante movimento de fragilização de fronteiras.

Com isso, pretendemos afirmar o primado da diversidade dos usos linguísticos como eixo estruturante das reflexões que atravessam diferentes áreas de conhecimento. Trata-se de diversidade que ultrapassa aqueles fenômenos utilizados para demonstrações em sua tematização, mas de um princípio que atravessa os usos e contribui para a construção de um posicionamento inerente a qualquer texto.

Eis, desse modo, a aposta que fazemos para a formação de novos professores de língua portuguesa: proporcionar ao licenciando uma experiência de contato com uma língua que vem se formando, na qual se reconhecerão, então, processos em desenvolvimento, e não retratos estáticos de perfis de língua submetidos a julgamento de valor, segundo o 
qual uma certa variedade é tida como boa, ocupando as demais a condição de "reproduções imperfeitas" de um modelo irremediavelmente perdido.

\section{Referências}

BAKHTIN, M. Problemas da poética de Dostoiévski. Rio de Janeiro: Forense Universitária, 2013.

COLLING, L. O que perdemos com os preconceitos? CULT - Revista Brasileira de Cultura, São Paulo, Bregantini, n. 202, jun. 2015. Disponível em: <http://revistacult.uol.com.br/home/2015/06/o-que-perdemos-comos-preconceitos/>. Acesso em: 5 set. 2016.

DELEUZE, G.; GUATTARI, F. Mil platôs. Tradução de A. L. de Oliveira, A. G. Neto e C. P. Costa. São Paulo: Ed. 34, 2007. v. 1.

DUARTE, V. M. do N. Variações linguísticas. Brasil Escola, [s.d.]. Disponível em: $<$ http://brasilescola.uol.com.br/gramatica/variacoeslinguisticas.htm>. Acesso em: 15 ago. 2016.

HORA, D. da; TELLES, S.; MONARETTO, V. N. O. português brasileiro: uma língua de metátese? Letras de Hoje, Porto Alegre, v. 42, n. 2, p. 178-196, set. 2007.

MAINGUENEAU, D. Discurso literário. Tradução de Adail Sobral. São Paulo: Contexto, 2006.

MAINGUENEAU, D. O contexto da obra literária. Tradução de M. Appenzeller. São Paulo: Martins Fontes, 2001.

MAINGUENEAU, D.; COSSUTA, F. L'analyse des discours constituants. Langages, Paris, Larousse, v. 29, n. 117, p. 112-125, 1995.

NERY, A. Variações linguísticas: o modo de falar do brasileiro. $U O L$ Educação, 26 mar. 2007. Pesquisa escolar. Disponível em: <http:// educacao.uol.com.br/disciplinas/portugues/variacoes-linguisticas-omodo-de-falar-do-brasileiro.htm>. Acesso em: 1 ago. 2016.

NIETZSCHE, F. Sobre verdade e mentira no sentido extramoral. In: . Obras incompletas. Seleção de Gérard Lebrun. São Paulo: Abril Cultural, 1978. 
PASSOS, E.; BARROS, R. B. de. A cartografia como método de pesquisaintervenção. In: PASSOS, E.; KASTRUP, V.; ESCÓSSIA, L. da (Org.). Pistas do método da cartografia: pesquisa-intervenção e produção de subjetividade. Porto Alegre: Sulina, 2009. p. 17-31.

PASSOS, E.; KASTRUP, V.; ESCÓSSIA, L. da (Org.). Pistas do método da cartografia: pesquisa-intervenção e produção de subjetividade. Porto Alegre: Sulina, 2009.

PASSOS, E.; KASTRUP, V.; TEDESCO, S. Pistas do método da cartografia: a experiência da pesquisa e o plano comum. Porto Alegre: Sulina, 2014.

PATATIVA DO ASSARÉ. Inspiração nordestina. São Paulo: Hedra, 2006.

PINHEIRO, S. Patativa do Assaré: entre o oral e o escrito. Diadorim, Rio de Janeiro, v. 1, p. 135-149, 2006.

ROCHA, D.; DEUSDARA, B. Práticas de linguagem e produção de subjetividade: dimensões interdisciplinares dos discursos midiáticos. Revista Intercâmbio, São Paulo, v. XXIV, p. 165-180, 2011.

ROLNIK, S. Cartografia sentimental: transformações contemporâneas do desejo. Porto Alegre: Sulina, Ed. da UFRGS, 2007.

ROMAGNOLI, R. C. A cartografia e a relação pesquisa e vida. Psicologia \& Sociedade, Associação Brasileira de Psicologia Social, v. 21, n. 2, p. 166-173, 2009. Disponível em: <http://www.scielo.br/pdf/psoc/v21n2/ v21n2a03.pdf>. Acesso em: 1 ago. 2016.

ROSSI, A.; PASSOS, E. Análise institucional: revisão conceitual e nuances da pesquisa-intervenção no Brasil. Epos, Rio de Janeiro, v. 5, n. 1, p. 156-181, 2014. Disponível em: <http://pepsic.bvsalud.org/pdf/epos/ v5n1/09.pdf $>$. Acesso em: 4 jan. 2017. 